electron might have been a representation of the proton. His firm belief that physics should follow "standard mathematics" is expressed very strongly in these lectures, and brings him to the point (p36) where he is willing to give up special relativity rather than accept renormalisation. One finds this a somewhat strange opinion from the man who, after all, introduced the $\delta$-function into physics at a time when it was mathematically disreputable. The picture which he gives of the early days of quantum mechanics is most interesting, and there is one especially quotable remark, namely that "it was very easy in those

\section{From quarks via tokamaks, to quasars}

\section{P. 'T. Matthews}

A Perspective of Physics. Vol. 2. Selections from 1977 Comments on Modern Physics. Introduced by Rudolf Peierls. (Gordon and Breach: London, New York and Paris, 1978.) $£ 16.70$.

Up to the outbreak of World War II the physicists who had discovered quantum mechanics and were engaged in developing its exciting implications in nuclear, atomic, molecular and solid-state physics and astrophysics, formed a close-knit international group, small enough for each individual to follow in some detail the activities of the whole. When work on basic physics started up again after the War, it was in much the same spirit; and it was not unreasonable to attempt to keep pace with the published literature as it appeared. This did not last long. The search for fundamentals led to a whole new international community of high energy, or elementary particle physicists, working in the newly discovered sub-nuclear domain, while each of the separate areas mentioned above developed into a major field of operation with its private army of specialists communicating within its own boundaries through an ever increasing flood of specialised literature.

The pace got hotter and by the mid1950s the published literature became largely irrelevant because it took too long for an important advance to appear in print. Research groups working on related topics all over the world, but particularly in Western Europe and America, started communicating with each other by exchange of pre-prints and conference days for any second-rate physicist to do first-rate work ... It is very difficult now for a first-rate physicist to do second-rate work". While accepting the latter proposition, we may remain somewhat sceptical about the former.

This book of lectures goes beyond history, although already interesting for that reason, and gives us also an interesting picture of Professor Dirac's ideas of recent years. Altogether, the book is very stimulating to read and deserves a place in every science library.

R. H. Dalitz is Royal Society Research Professor in the Department of Theoretical Physics at the University of Oxford, UK.

reports. This scientific samisdat, even within a discipline such as high energy physics, tended to produce a fragmentation into subgroups very well informed within their own narrow speciality but increasingly isolated from each other. In 1967 Comments on $\mathrm{Nu}$ clear and Particle Physics was founded in a deliberate effort to counteract this trend. In the foreword to the opening volume it is explained that a group of distinguished physicists will each be asked "to comment on work that seems to him interesting and important" in the hope that new ideas would be made available "not only to specialists in the field, but also to colleagues working in related and unrelated areas of physics". Other issues in other fields followed and although the appearance of Comments did not change the face of physics, there is no doubt that over the years it has helped to break down the barriers of overspecialisation.

The volume under review is the second in an annual series which takes this process one stage further. It consists of a selection of reprints of some 25 articles which have appeared in

\section{Mechanism of organic evolution}

Evolution. By C. Patterson. Pp. 197. (Routledge and Kegan Paul, in association with the British Museum (Natural History): London, 1978.) Hardback £5.95; paperback £2.95.

AT the time of the Fifteenth International Congress of Zoology in 1958, the Natural History Museum in South Kensington, London, under Sir Gavin de Beer mounted a "permanent" evolution exhibit in the Main Hall of the Museum to commemorate in part the paper by Darwin and Wallace "On the Tendency of Species to form Varieties; and on the Perpetuation of Varieties
Comments on Modern Physics during 1977. The selection has been made by Sir Rudolph Peierls. The articles are split fairly evenly under the five main headings of nuclear and particle physics, solid-state, astrophysics, atomic and molecular and finally plasma physics. The selection is preceded by an introduction written by Sir Rudolph which straddles the whole field and so puts the individual articles into some coherent context. As the blurb on the dust cover rather grandly says, the whole is an attempt "to keep both the specialist reader and interested observer abreast of the most significant developments in all modern physics".

This is a very ambitious project which probably succeeds as well as could be expected, almost exclusively as a result of Peierls' masterly introduction. Without it the collected reprints would be a jumble of fragments which would add up to very little indeed. In 25 pages, which are commendably free from specialist jargon which so often obscures such articles, Peierls gives a broad brush account of the whole hackground which places each of the separate papers in an intelligible relation to the rest. The fact that this is done by someone already some years past official retirement, demonstrates by example that physics is still a coherent whole, and that one man prepared to make the effort can still see it as such and can follow its major developments all the way from quarks. via tokamaks. to quasars.

Professor P. T. Matthews was Head of the Department of Physics, Blackett Laboratory, Imperial College, from 1971-76, and is now Vice-Chancellor of the University of Bath, UK.

and Species by Natural Means of Selection", read at a meeting of the Linnean Society in London on 1st July 1858. To accompany the Exhibition, the Museum published $A$ Handbook on Evolution, consisting of a general essay on natural selection and a guide to the exhibits. This Handbook was used by generations of students.

Twenty years later, the evolution exhibit has gone and the 1958 Handbook now seems very superficial. We are promised a new exhibit at the Museum in due course but in the meantime the Museum's Trustees (in association with Routledge and Kegan Paul) have produced a really excellent small book on Evolution by Colin Patterson, who works on fossil fish at the Museum. This is a completely new book which describes and summarises 